\title{
Establishment of simple criteria for the identification of cassava clones produced in Côte d'Ivoire
}

\author{
Karidia TRAORE*, Moussa SYLLA, Issouf BAMBA and Check OUATTARA \\ Université Jean Lorougnon Guédé, BP 150 Daloa. \\ "Corresponding author, E-mail: kadytrao@yahoo.fr; Tél: (+225) $05089166 /$ (+225) 47936044.
}

\begin{abstract}
In Côte d'Ivoire, cassava is widely grown all over the country, and a large variety of varieties is encountered. This diversity is due, on the one hand, to the fact that genotypes respond differently to various soil, climate and biotic factors and, on the other hand, to the continuous exchange of seeds among producers. The objective of this study was to find a limited number of reliable and stable morphological criteria that would allow clones to be identified throughout the cassava chain. The study first consisted of a visit in the experimental station with the aim of identifying all the clones found on the different plots. Twenty clones were randomly selected. Then, cassava descriptors developed by the International Institute of Tropical Agriculture (IITA) were used to identify differences between these clones. The PCA analysis method highlighted seven main criteria: "color of the last branch", "color of the leaf", "color of the petiole", "color of the rib", "number of branches", "profile of the petioles" and " shape of the branches". These criteria made it possible to differentiate eleven clones.
\end{abstract}

(C) 2019 International Formulae Group. All rights reserved

Keywords: cassava, clone, criterion, morphology, Côte d'Ivoire.

\section{INTRODUCTION}

Cassava (Manihot esculenta Crantz) was introduced into Latin America in the late 16th century (Guira et al., 2016). Since then, it has spread to sub-Saharan Africa and has become the staple food of many populations. Indeed, cassava is now the third most important source of calories in the tropics after rice and maize (Food Safety Network, 2014). Originally a subsistence crop, it tends to become a cash crop by providing substantial income to producers. The world output is estimated to be about 163.8 million tonnes, with $50 \%$ in Africa, where Nigeria is the leading producer with 31.4 million tonnes (Akinpelu et al., 2011). Côte d'Ivoire produces about 2 million tonnes, yielding between 5 and 8 tonnes per hectare (Nzué et al., 2008). Cassava is one of the most widely consumed foods due to its diversity of processing in this country. It has the benefit of being used from leaves to roots. The most well known format is attiéké (Koko et al., 2014).

In Côte d'Ivoire, Cassava is grown countrywide. However, there is a wide variability of varieties in the growing areas. This diversity is related, on the one hand, to the fact that genotypes respond differently to various soil, climatic and biotic factors and, on the other hand, to the continuous exchange of seeds between producers. These movements of cassava seeds between producers not only help to conserve and protect variety diversity, but also provide 
indications of farmers' preferences for cassava tubers. To distinguish between different cassava genotypes, producers use local names that are generally indicative of the physical characteristics of the plants, such as the color of certain organs, the size and type of foliage, yield potential, etc. These names may also describe the original source of the genotype or indicate an event that coincides with the introduction of the genotype. However, these names are very little useful in a classification of genotypes because the same genotype can have several names depending on the villages, and different genotypes can have the same name, especially when considering the names related to the source of introduction (Koko et al., 2012 ; Gnonlonfin et al., 2011).

Several techniques, including molecular, biological and morphological techniques, make it possible to establish the authenticity of the crop material. However, the analysis of morphological descriptors seems the cheapest and reveals the diversity as perceived and adopted by local farmers; the main actors of the varietal diversity (Mckey et al., 2001; Empaire et al., 2003).

The objective of this study is to find a set of reliable and stable morphological criteria that would allow clones to be identified throughout the cassava chain. More specifically, it aims to (1) identify the descriptive criteria of the different clones, (2) characterize the different clones by these criteria.

\section{MATERIALS AND METHODS \\ Material \\ Study site}

The study took place in the town of Azaguié, (about $36 \mathrm{~km}$ from Abidjan) in the department of Agboville (figure 1) and at Nangui Abrogoua University (UNA) located between Abobo and Adjamé in Abidjan.

\section{Biological material}

The genus Manihot belongs to the tribe of Manihotae of the Euphorbiaceae family. There are 99 known species but only one of which is grown for tuberized roots : Manihot esculenta Crantz (Koko et al., 2014). The plant material investigated in the study consisted of 20 clones of Manihot esculenta collected during survey missions in selected cassava production areas in Côte d'Ivoire These clones are: A4c, A4g, A4d, A8a, A5a, A20c, 135a, A1a, A1a, 165a, 162c, A110a, 110b, A100c, A14a, 133a, 131a, 142a, 82b, $137 \mathrm{c}, \mathrm{A} 25 \mathrm{e}$.

\section{Methodology \\ Experimental setup}

The plots on which this work was carried out had an area of approximately 2500 $\mathrm{m}^{2}$ each. The field was plowed into ridges that formed the rows. Each row included ten (10) individuals corresponding to a clone from one locality in Côte d'Ivoire. Overall, the experimental field consisted of 210 rows of 2100 cassava plants corresponding to the different clones. It should also be noted that the varieties present on the Azaguié experimental field were old (six months and over), and those present on the UNA plot were young (three months).

\section{Description of the different clones}

The study started by going through the experimental station in order to identify all the clones present on the different plots. The clones were randomly selected using a simple sampling method (Nadjiam et al., 2016). This method consisted of randomly and independently selecting healthy, vigorous plants representative of the clone from the plot. The study included twenty (20) clones that were selected and labelled. Morphological criteria were identified and subsequently allowed differences between clones to be identified. Morphological characterization was made possible by observations made using cassava descriptors developed by researchers at the International Institute of Tropical Agriculture (IITA) (Fukuda et al., 2010). The selected characteristics are contained in Table 1. For each clone, ten (10) individuals were observed; this makes a total of two hundred (200) individuals observed for the entire study. The color and pubescence of the apical bud were observed on three (3) month varieties and the other criteria were observed on plants aged six (6) months and over.

\section{Statistical analysis}

The collected data were input into an Excel table in the form of an "Accessions X (times) Morphological characteristics" matrix. 
This matrix was subjected to multivariate analyses to discriminate access groups according to their morphological characteristics.

Principal component analysis (PCA) was used to identify the distinctive criteria of clones. The PCA is an essentially descriptive method that presents the distribution of the subjects in relation to all the variables correlated with each other into new variables in a graphical form. The analysis allows the accessions to be projected on a plane whose axes are defined as new independent composite variables. Each axis (composite variable) is a combination of morphological descriptors weighted by their level of explanation of the overall variability of the system. Thus, the representation optimizes the morphological variability between accessions, the distribution of the individuals in the analysis in relation to all the variables correlated with each other into new variables that are independent of each other. These new variables are called "main components" or main axes. PCA reduces the number of variables and makes information less redundant (Djaha et al., 2017). It was done using XLSTAT software version 2014.4.04.

The PCA was first conducted with twenty-seven (27) selected criteria. Then, the analysis was repeated several times until a graphical representation could be obtained which best expressed the observed variability between the twenty (20) clones. For this purpose, the criteria least correlated to the axis F1 and F2 were gradually eliminated. Also, among the criteria correlated with each other, only those that are easily observable or measurable were selected. The criteria thus obtained are referred to as "main criteria".

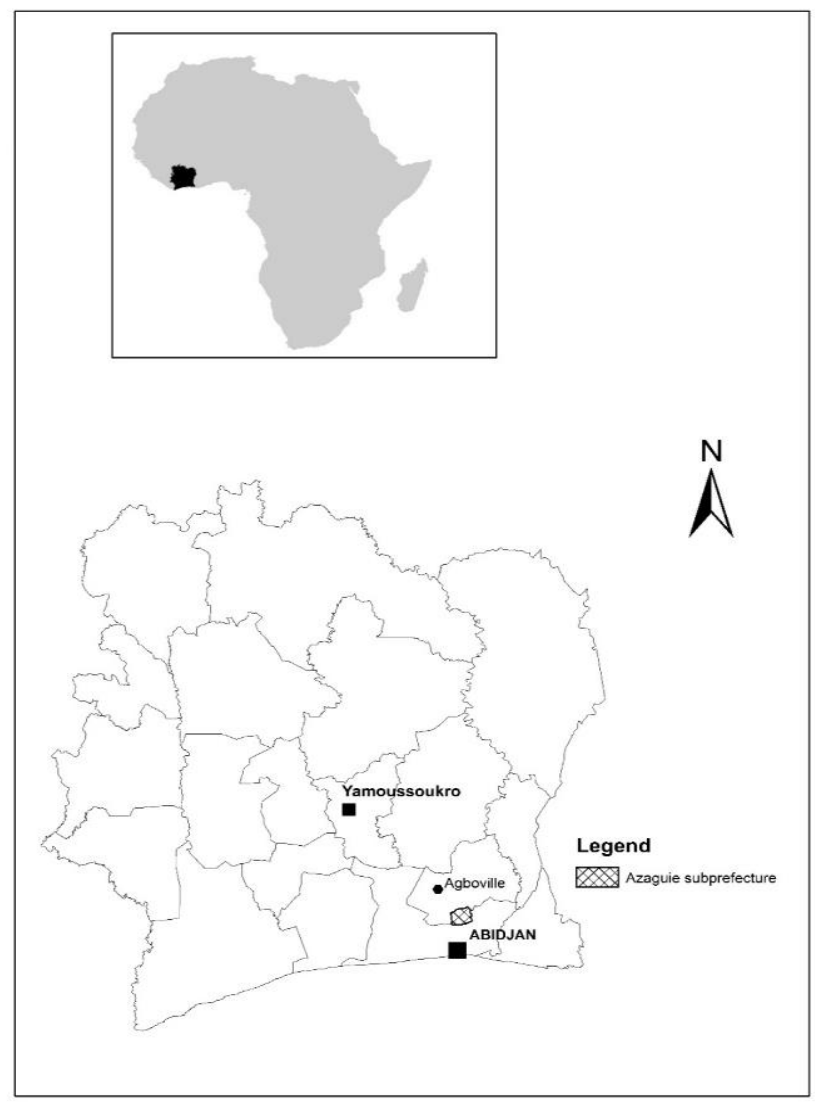

Figure 1: Localization of study area in the southern part of the Côte d'Ivoire. 
Table 1: Set of criteria used for the description of clones.

\begin{tabular}{|c|c|}
\hline Descriptor number & Characters \\
\hline 1 & Color of the apical bud \\
\hline 2 & Pubescence of the apical bud \\
\hline 3 & Leaf relief \\
\hline 4 & Nature of the leaf end \\
\hline 6 & color of Rib \\
\hline 6 & color of Petiole \\
\hline 7 & Petiole length \\
\hline 8 & Petiole profile \\
\hline 9 & Number of lobes \\
\hline 10 & Central lobe length \\
\hline 11 & Width of the central lobe \\
\hline 12 & Shape of the central lobe \\
\hline 13 & Sheet color \\
\hline 14 & Importance of the petiolar scar \\
\hline 15 & Color of the pulpit of the root \\
\hline 16 & Color of the cortex of the root \\
\hline 17 & Root shape \\
\hline 18 & Root texture \\
\hline 19 & Total height of the plant \\
\hline 20 & Height of the first branch \\
\hline 21 & Number of branches \\
\hline 22 & Branch plan \\
\hline 23 & Color of the rod \\
\hline 24 & Stem growth mode \\
\hline 25 & Rod diameter \\
\hline 26 & Distance between eyes \\
\hline 27 & Root stalk \\
\hline 28 & Flowering \\
\hline 29 & Seed \\
\hline 30 & Fruit \\
\hline 31 & Architecture \\
\hline 32 & Colour of the last branch \\
\hline
\end{tabular}




\section{RESULTS}

\section{Criteria identification}

The results of the various observations present a high number of criteria that do not allow the different clones to be distinguished. The PCA was therefore used to highlight the relevant criteria.

The first PCA carried out on the descriptions of all clones showed that the combination of the twenty-seven (27) criteria selected from the thirty-three (33) used for the description expressed only $35.15 \%$ of the morphological variability between the twenty (20) clones. The best expression of variability between clones was obtained by combining only seven (7) criteria, including " number of branches ", " branch plane ", " rib color ", " petiole profile ", and " petiole color ", " last branch color " and " leaf color ". These criteria were selected based on their significance (Figure 2). Indeed, these seven criteria expressed $73.42 \%$ of the total variability observed between clones. The F1 axis expresses $38.17 \%$ of the total variability and is linked to the criteria "Color of the last branch", "Color of the rib", "Color of the leaf", "Color of the petiole". Axis F2 is positively correlated to the "number of branches" and negatively to the "petiole profile" and the "branch plane". All seven criteria were not significant on axis F3.

These so-called "main" criteria made it possible to identify eleven (11) clones, namely 137c, 165a, A25e, A100c, A110a, A4d, A20c, 82b, A14a, 110b, 133a. Therefore, these criteria, which distinguished $73.42 \%$ of the variability expressed by these eleven clones, could not isolate the nine (9) others, which are: A1a, 131a, 142a, 162c, 135a, A8a, A5a, $\mathrm{A} 4 \mathrm{~g}, \mathrm{~A} 4 \mathrm{c}$.

\section{Morphological characterization of the different clones}

The PCAs showed eleven (11) clones discriminated based on some morphological criteria (figure 3 and figure 4). These clones descripted below are 137c, 165a, 25e, A100c, 110a, 110b, 82b, A20c, A4d, 133a and A14a.

$>137 \mathrm{c}$ : This clone is characterized by downwardly oriented red petioles, a pure red vein. It has no branches, the branches are completely erected with a last branch that is all red.

165a: The petioles of this clone are red and upwardly oriented, the vein and leaf are green. It is slightly branched with trichotomous branches and the last branch is red-green.

A25e: Its petioles are green except at the ends. The leaf and vein are green, it is not very branched with trichotomous branches. The last branch is all green.

A100c: This clone has green petioles except at the ends, the leaf and vein are green. It is moderately branched (10-17 branches) with a dichotomous branch plane. The last branch is also all green.

$>$ 110a: It differs from the previous one in the number of branches because it is not very branched, the A100c and 110a clones are the only ones with pure green leaves.

$>$ 110b: Facing upwards, the petioles and veins are red. This clone is not very branched with dichotomous branches. The last branch is red and green

$>$ 82b: The petioles of this clone are green except at the ends and are irregularly arranged. It is slightly branched (10-17 branches) with dichotomous branches. The last branch is red and green.

A20c: This clone has pure, upwardly oriented red petioles, the veins are red. It is moderately branched with trichotomous branches. The last branch is red and green.

A4d: It differs from the previous one in the pure red color of the rib.

$>$ 133a: The petioles are pure red with green veins when positioned upwards. It is moderately branched with dichotomous 
branches. The last branch is red and green. The particularity of this clone is that it is small in size $(150$ to $170 \mathrm{~cm})$.

$>$ A14a: Facing upwards, the petioles and veins of this clone are red. It is strongly branched (more than 20 branches) and has trichotomous branches. The last branch is red and green.

\section{DISCUSSION}

The morphological characterization is one of the most important steps in the description and phenotypical classification of cultured plants. Indeed, any improvement program necessarily relies on phenological variability (Fukuda et al, 2010). It makes it possible to provide breeders and farmers with vital information required for their work. In this context, a local collection of twenty (20) varieties of cassava collected from certain regions of Côte d'Ivoire was investigated using morphological parameters.

The choice of distinctive morphological criteria allowed to identify thirty-one (33) useful characters that were used to describe these cassava clones placed in the Azaguié and Nangui Abrogoua University experimental field. The PCA showed seven (7) main characters and six (6) secondary characters. This reflects significant inter-accession variability. This high morphological diversity is believed to result from seed management practices. Several authors have demonstrated that peasant seed management practices, particularly variety transfers between farmers, are at the basis of a high diversity between cultivated plant communities (Mc Key et al., 2001; Barnaud et al., 2008; Delaunay et al., 2008).
In addition to this fact, the diversity observed on plant material brought back from peasant fields and maintained in stations differs from that observed when cultivars are considered in their growing environment. This idea is supported by Nadjiam et al. (2016) who discriminated cassava cultivars in relation to their origin region by showing that the number of the leaf lobes can vary with climate, soil and altitude

The presence of some long stalks preceding the roots seems to be a character more related to the areas. The results of this study showed that the main criteria correlated to axis F1 and F2 are the colors of the last branch, the petiole of the rib, the last branch, the leaf, the petiole profile, the number of branches and the branch plane. These results are different from those of Kosh-Konba et al (2014) who found that the main distinguishing criteria are leaf architecture, stipule size and leaf retention capacity. Variation within a descriptor can also influence the structure of diversity. In addition, the use of morphological markers is influenced by the environment as corroborated studies on cultivated Jujube in China (Li et al., 2015).

Molecular markers are preferred for such studies since they cannot be influenced by environmental factors. A comparison of the phenotypic features of varieties grown by Makushi Amerindians in the experimental garden by Elias et al. (2001) showed that the different accessions of a local group show inheritable genetic variation in morphological features and the plasticity of expression of these traits as a function of the environment. 


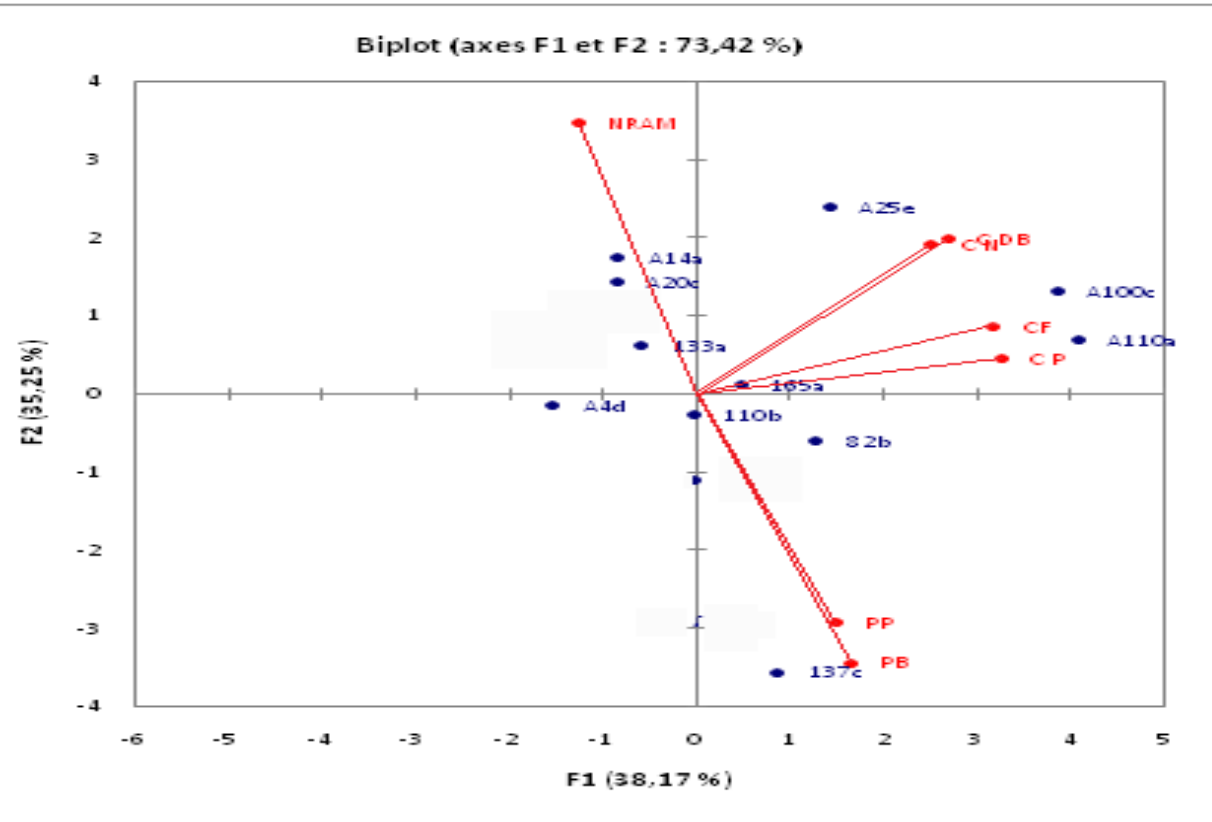

Figure 2: Distribution of the 11 clones according to the 7 main criteria identified

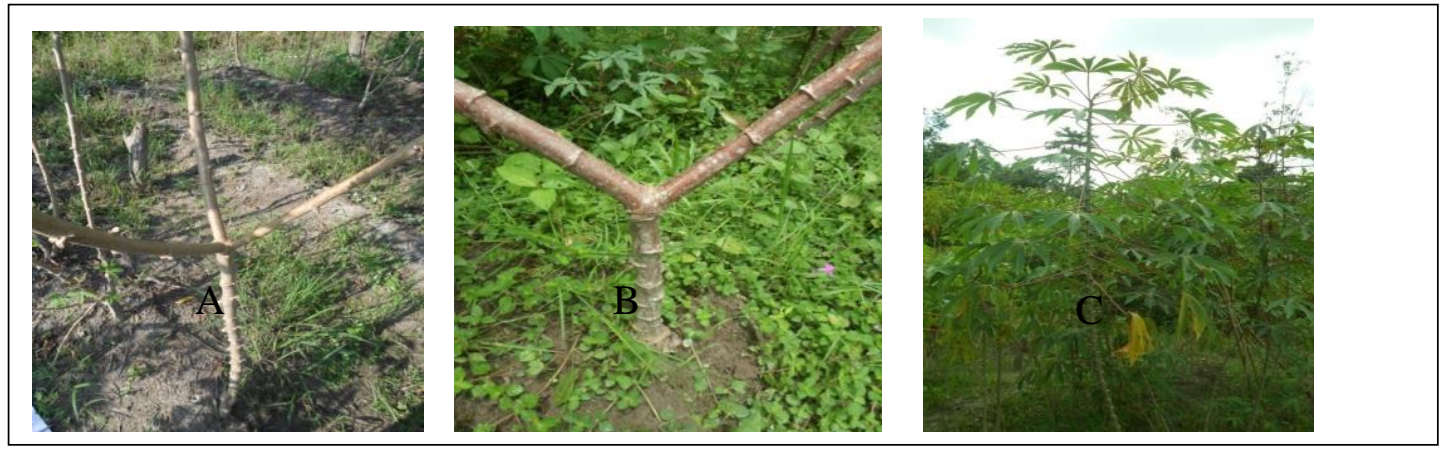

Figure 3: Types of branching (A: Trichotomous, B: Dichotomous, C: Unbranched)

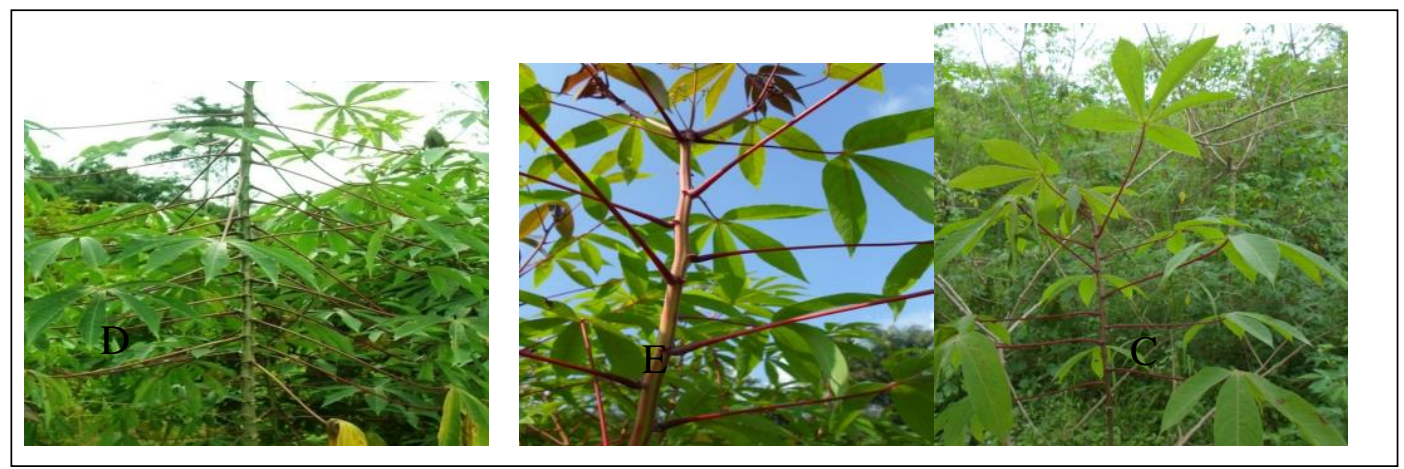

Figures 4: Different types of petioles orientation (D: downward orientation, E: upward orientation, F: irregular orientation). 


\section{Conclusion}

The study of the morphological diversity of the twenty (20) cassava clones, Manihot esculenta (Crantz), carried out in the experimental stations of Azaguié and Nangui Abrogoua University, made it possible to select many criteria that could differentiate these clones. Indeed, thirty-three (33) criteria were used to conduct this study; but among these criteria, some were more relevant. The ACP analysis method revealed main criteria which are " color of the last branch ", " color of the leaf ", " color of the petiole ", " color of the rib ", " number of branches ", " profile of the petioles " and " plane of the branches ". These criteria made it possible to differentiate eleven clones. Thus, a considerable diversity of morphological types of cassava is present in the different localities of Côte d'Ivoire. This work has also shown that the use of morphological criteria for the identification of cassava clones is an effective solution since it can be easily used by the various stakeholders in the sector. This study is not exclusive, it deserves to be extended to all clones present in Côte d'Ivoire to better understand morphological diversity. It would also be necessary to analyze the structuring of the current genetic diversity and define a correlation.

\section{COMPETING INTERESTS}

The authors declare that they have no competing interests.

\section{AUTHORS' CONTRIBUTIONS}

KT was responsible for setting the protocol and contributed to the writing of this paper. MS and CO set up the tests, collected the data and participated in the production of this paper. IB processed the data statistically and contributed with the writing of the article.

\section{ACKNOWLEDGMENTS}

This work could not have been achieved unless the support of the Centre National de Recherche Agronomique (CNRA) and L'Université Nangui Abrogoua (UNA). The CNRA provided us with some of the plant material (cassava clone) and part of the the tests were conducted at one of its stations in Azaguié. We would like to thank the Director General of the CNRA, Mr Yté Wongbé and his collaborators. We also are grateful to the President of UNA, Professor TANO Yao, for letting us set up part of our experiments at the University.

\section{REFERENCES}

Akinpelu AO, Amamgbo LEF, Olojede AO, Oyekale AS. 2011. Health Implications of cassava Production and Consumption, Journal of Agriculture and Social Research (JASR), 11(1): $118-125$.

Barnaud A, Joly H, McKey D, Deu M, Khasah C , Monné S, Garine E. 2008. Gestion des ressources génétiques du sorgho (Sorghum bicolor) chez les Doupa (Nord Cameroun). Cahiers Agriculture, 17(2) : 178-182.

Delaunay S, Tescar R-P, Oualbego A, Vom Brocke K, Lançon J. 2008. La culture du coton ne bouleverse pas les échanges traditionnels de semences de sorgho. Cahiers Agriculture, 17 : 189-194.

Djaha KE, Abo K, Bonny BS, Kone T, Amouakon WJL, Kone D, Kone M. $2017 . \quad$ Agromorphological characterization of 44 accessions of cassava (Manihot esculenta Crantz) grown in Côte d'Ivoire. Int. J. Biol. Chem. Sci., 11(1): 174-184.

Dulong R. 1971. Le manioc à Madagascar. L'Agronomie Tropicale, 26(8): 791-826.

Emperaire L, Gilda S M, Fleury M, Robert T, Mckey D, Pujol B. 2003. Approche comparative de la diversité génétique et de la diversité morphologique des maniocs en Amazonie (Brésil et Guyanes). Actes du BRG, 4 : 247-267.

Fukuda WMG, Guevara CL, Kawuri R, Ferguson ME. 2010. Selected morphological and agronomic descripteurs for the characterization of cassava, IITA, Nigeria, pp 19.

Food Safety Network. 2014. Cassava Nutritional Network. 1-866-50-FS-NET. University of Guelph, March 14, 2005; 2 pages. 
Guira F, Some K, Kaboré D, SawadogoLingani $\mathrm{H}$, Traore $\mathrm{Y}$, Savadogo A. 2016. Origins, Production, and utilization of cassava in Burkina Faso, a contribution of a neglected crop to household food security. Food Science \& Nutrition, 5(3): $\quad 1-9 . \quad$ DOI: $10.1002 /$ fsn 3.408

Gnonlonfin GJB, Koudande DO, Sanni A, Brimer L. 2011. Farmers' perceptions on characteristics of cassava (Manihot esculenta Crantz) varieties used for chips production in rural areas in Benin, West Africa. Int. J. Biol. Chem. Sci., 5(3): 870-879.

Koko CA, Kouame KB, Assidjo E, Amani G. 2014. Characterization and Utilization of Fermented cassava Flour in Breadmaking and Placali Preparation. Int. J. Biol. Chem. Sci., 8(6): 2478-2493.

Koko CA, Konan A , Tétchi F , Assidjo E, Amani G. 2012. Quality of fermented cassava flour processed into placali. Int. J. Biol. Chem. Sci., 6(1): 415-420.

Kosh-Komba E, Akpavi S, Woegan YA, Atato A, Duval MF, Dourma M, Zinga I, Longue D, Semballa S. 2014. Diversité agromorphologique de Manihot esculenta Crantz. (Euphorbiaceae) cultivée dans trois zones agroclimatiques en République centrafricaine (RCA). European Scientific Journal, 10(3) : 365380.

Lefèvre F. 1988. Ressources génétiques et amélioration du manioc (Manihot esculenta) en Afrique. Thèse de Doctorat de l'Institut National Agronomique Paris-Grignon, Paris, France. 181 p.
Li X, Li Y, Zhang Z, Li X. 2015. Influences of Environmental Factors on Leaf Morphology of Chinese Jujubes. PLoS ONE, 10(5): e0127825. DOI : https://doi.org/10.1371/journal.pone.012 7825

McKey D, Emperaire L, Elias M, Pinton F, Robert T, Desmoulière S, Rival L. 2001. Gestions locales et dynamiques régionales de la diversité variétale du manioc en Amazonie. Genet. Sel. Evol., 33 : 465-490.

Nadjiam D, Sarr PS, Naïtormbaïdé M, Mbaïguinam JMM, Guisse A. 2016. Agro-Morphological Characterization of Cassava (Manihot esculenta Crantz) Cultivars from Chad. Agricultural Sciences, 7: 479-492. DOI : http://dx.doi.org/10.4236/as.2016.77049

N'zué B, Zohouri G, Yapi GV, Djédi C. 2008. Bien cultiver le manioc, CNRA, $6 \mathrm{p}$.

Rabbi IY, Kulakow PA, Manu-Aduening JA, Dankyi AA, Asibuo JY, Parkes EY, Abdoulaye T, Girma G, Gedil MA, Ramu P, Reyes B, Maredia MK. 2015. Tracking crop varieties using genotyping-by-sequencing markers: a case study using cassava (Manihot esculenta Crantz). BMC Genet., 16:115. DOI: 10.1186/s12863-015-0273-1.

Robert T. 2001. Traditional the management of cassava morphological and genetic diversity by the Makushi Amerindians (Guyana, South America): Perspectives for on farm conservation of crop genetic resources. Euphytica, 120: 143-157. 